\title{
Inovasi Model Pembelajaran POE2WE dengan Berbasis Savi (Somatic, Auditory, Visual, Intellectual) Pada Materi Fisika
}

\author{
Ilham mubarok \\ Pendidikan Fisika FKIP Universitas Siliwangi \\ Tasikmalaya Jawa Barat Indonesia \\ Email: ilhammubarok05@gmail.com
}

\begin{abstract}
Abstrak - Penelitian ini bertujuan untuk (1) mengetahui apakah penggunaan model (Prediction, Observation, Explanation, Elaboration, Write dan Evaluation) POE2WE berbasis (Somatic, Auditory, Visual, Intellectual) SAVI dapat meningkatkan hasil belajar peserta didik (2) mengetahui besarnya hasil belajar fisika peserta didik sebelum diterapkan Model pembelajaran POE2WE berbasis SAVI (3) mengetahui besarnya hasil belajar fisika peserta didik setelah diterapkan Model pembelajaran POE2WE berbasis SAVI. Pendekatan SAVI memberikan kolaborasi keintelektualan siswa yang didukung aspek auditori dan visual dalam pembelajaran serta melatih siswa untuk mampu menyelesaikan masalah yang ditemuinya. Penelitian ini merupakan penelitian studi pustaka dan tes soal dengan variabel tertutup. Penelitian ini dilaksanakan di mahasiswa universitas siliwangi yang berjumlah 32 mahasiswa. Teknik pengumpulan data yang digunakan adalah tes hasil belajar yang terdiri dari 10 soal dalam bentuk pilihan ganda. Analisis deskriptif menunjukkan nilai rata-rata hasil belajar fisika sebelum diajar menggunakan Model pembelajaran POE2WE berbasis SAVI sebesar $75 \%$ dan setelah diajar dengan menggunakan Model pembelajaran POE2WE berbasis SAVI sebesar 81\%. Dari hasil analisis dapat disimpulkan bahwa Model pembelajaran POE2WE berbasis SAVI dapat meningkatkan hasil belajar fisika peserta didik.
\end{abstract}

Key words: POE2WE, SAVI, Fisika

\begin{abstract}
This study aims to (1) determine whether the use of models (Prediction, Observation, Explanation, Elaboration, Write and Evaluation) based on POE2WE (Somatic, Auditory, Visual, Intellectual) SAVI can improve student learning outcomes (2) know the magnitude of physics learning outcomes students before applying the SAVI-based POE2WE learning model (3) knowing the magnitude of the physics learning outcomes of students after applying the SAVI-based POE2WE learning model. The SAVI approach provides student intellectual collaboration supported by auditory and visual aspects in learning and trains students to be able to solve the problems they encounter. This research is a literature study and a test item with closed variables. This research was conducted at Siliwangi University students, amounting to 32 students. The data collection technique used was a learning achievement test consisting of 10 questions in the form of multiple choice. Descriptive analysis shows the average value of physics learning outcomes before being taught using the SAVI-based POE2WE learning model at $75 \%$ and after being taught using the SAVI-based POE2WE learning model at $81 \%$. From the results of the analysis it can be concluded that the SAVI-based POE2WE learning model can improve students' physics learning outcomes.
\end{abstract}

Kata kunci: POE2WE, SAVI, Physics

\section{PENDAHULUAN}

Pendidikan merupakan suatu pengaruh untuk bangsa menjadi lebih maju dan berkembang. Pendidikan mempunyai peran yang sangat strategis dalam meningkatkan kualitas sumber daya manusia oleh karena itu pendidikan selalu diharapkan mengalami peningkatan dari waktu ke waktu. Upaya peningkatan mutu pendidikan pada saat ini terus dilakukan oleh berbagai pihak. Namun salah satu masalah yang dihadapi saat ini adalah rendahnya kualitas pendidikan. Salah satu faktor rendahnya kualitas pendidikan 
adalah pada proses pembelajaran yang kurang efektif khususnya pada pembelajaran fisika yang sering didominasi oleh pembelajaran yang berpusat pada guru selain itu kurangnya keaktifan peserta didik dalam proses pembelajaran dan kurang didorong untuk mengembangan keterampilan berfikir. Kendala lain yang ditemukan dalam proses pembelajaran fisika adalah kurangnya kreatifitas guru dalam merancang dan menerapkan Metode pembelajaran yang relevan.

Kesalahan-kesalahan yang cenderung dilakukan para guru, khususnya guru fisika adalah sebagai berikut : (1) sering disajikan sebagai kumpulan konsep dan rumus yang harus dihafal oleh peserta didik, akibatnya ketika dilakukan evaluasi belajar, kumpulan konsep dan rumus tersebut campur aduk tak beraturan di benak peserta didik, (2) dalam menyampaikan materi kurang memperhatikan proporsi materi dan sistematika penyampaian, serta kurang menekankan pada konsep dasar, sehingga terasa sulit untuk peserta didik, (3) kurangnya variasi dalam pengajaran serta jarangnya digunakan alat bantu yang dapat memperjelas gambaran peserta didik tentang materi yang dipelajari, (4) kecenderungan untuk mempersulit, bukannya mempermudah. Ini sering dilakukan agar peserta didik tidak memandang remeh pelajaran fisika serta pengajar atau guru fisika (Monica, 2009).
Pembelajaran Fisika menurut Taufik (2010) dalam Noviyanti (2016) seharusnya dapat memberikan pengalaman langsung sehingga siswa dapat mengonstruksi, memahami, dan menerapkan konsep yang telah dipelajari. Pernyataan tersebut sejalan dengan Rahayu (2013) yang menjelaskan bahwa pembelajaran sains menuntut adanya interaksi antara siswa dengan objek yang dipelajari secara langsung yang sesuai dengan teori konstruktivisme, sehingga diharapkan akan tercipta proses belajar yang lebih baik.

Salah satu cara untuk meningkatkan mutu pendidikan adalah dengan menerapkan model pembelajaran POE2WE dengan bantuan berbasis SAVI.

Model pembelajaran (POE2WE) dikembangkan dari model pembelajaran POEW dan model pembelajaran Fisika dengan Pendekatan Konstruktivistik. Pengembangan ini dilakukan untuk sebagai penyempurnaan kedua model sebelumnya. Model POE2WE merupakan model pembelajaran yang dikembangkan untuk mengetahui pemahaman peserta didik mengenai suatu konsep dengan pendekatan konstruktivistik. Model ini membangun pengetahuan dengan urutan proses yaitu meramalkan atau memprediksi solusi dari permasalahan, melakukan eksperimen untuk membuktikan prediksi, kemudian menjelaskan hasil eksperimen yang diperoleh secara lisan maupun tertulis, membuat contoh penerapan dalam 
kehidupan seharihari, menuliskan hasil diskusi dan memuat evaluasi tentang pemahaman peserta didik baik secara lisan maupun tertulis (Nana et al., 2014, 2019).

Siswa memiliki tipe gaya belajar yang berbeda-beda, diantaranya: visual, auditori, dan somatis. Hannah (2009) menjelaskan bahwa menggabungkan gerakan fisik dengan aktivitas intelektual dan penggunaan indra dapat melibatkan siswa sepenuhnya dalam pembelajaran, sehingga berpengaruh positif terhadap hasil belajar siswa. Berdasarkan uraian tersebut diperlukan bahan ajar dengan pendekatan saintifik seutuhnya yang memperhatikan gaya belajar siswa.

Novianti dkk, (2016) menyatakan Model pembelajaran SAVI merupakan bagian dari pendekatan saintifik. Hal ini dikarenakan model pembelajaran SAVI memiliki empat gaya belajar, yaitu somatis, auditori, visual dan intelektual. Meier (2000) menegaskan bahwa belajar bisa optimal jika keempat gaya belajar dalam SAVI ada dalam satu peristiwa pembelajaran. Misalnya, seorang siswa dapat belajar sedikit dengan mengamati fenomena dalam kehidupan sehari-hari yang disajikan dalam modul (Visual). Namun, siswa dapat belajar jauh lebih banyak jika melakukan percobaan untuk mengumpulkan data (Somatic). Siswa memikirkan cara mengolah data hasil percobaan tersebut (variabel yang diukur) untuk menyelesaikan pertanyaan berdasarkan percobaan yang dilakukan (Intellectual). Siswa mengkomunikasikan hasil pengamatannya di depan kelas (Auditory). Cara belajar pada model SAVI adalah dengan mengajak siswa terlibat sepenuhnya. Pernyataan Meier tersebut diperkuat dengan hasil penelitian dari Gilakjani (2011:104) yang menjelaskan bahwa terdapat beberapa siswa yang lebih suka dengan gaya belajar visual, auditori, atau somatis. Siswa dapat menggunakan indra untuk menerima informasi dalam kegiatan belajar, sehingga mencapai hasil yang baik.

Model pembelajaran POE2WE berbasis SAVI ini dianggap cocok untuk mengatasi permasalahan peserta didik dalam proses pembelajaran fisika, karena model ini dapat membentuk dan mengembangkan konsep dasar dan penguasaan keterampilan peserta didik, mendorong peserta didik untuk berfikir kreatif dan bekerja atas inisiatifnya sendiri, jujur dan terbuka selain itu situasi dalam proses belajar menjadi lebih aktif, dan memberi kebebasan peserta didik untuk belajar sendiri.

Berdasarkan rumusan masalah di atas, maka tujuan dari penelitian ini adalah: Untuk mengetahui apakah penggunaan model pembelajaran POE2WE dengan berbasis SAVI dapat meningkatkan hasil belajar peserta didik.

\section{LANDASAN TEORI}

\section{A. Model Pembelajaran POE2WE}


Menurut Nana, dkk $(2014,2019)$ Model pembelajaran POE2WE dapat menjadikan peserta didik sebagai subjek di dalam pembelajaran. peserta didik secara aktif menemukan suatu konsep melalui pengamatan atau eksperimen secara langsung, bukan dari menghafal buku materi maupun penjelasan dari guru. Model ini memungkinkan peserta didik aktif dalam proses pembelajaran, memberikan kesempatan kepada peserta didik untuk mengkonstruksi pengetahuannya, mengkomunikasikan pemikirannya dan menuliskan hasil diskusinya sehingga peserta didik lebih menguasai dan memahami konsep yang akan berdampak pada peningkatan prestasi belajar peserta didik Model ini memberikan kesempatan kepada peserta didik untuk melakukan konstruksi pengetahuan yang dimilikinya, melakukan pengamatan terhadap fenomena serta mengkomunikasikan gagasan yang dia perolah dari proses diskusi sehingga peserta didik akan lebih mudah menguasai konsep yang diajarkan.

Tabel 1. Kegiatan pembelajaran Model Pembelajaran Model POE2WE

Sumber: Nana, Surahman E. 2019. Pengembangan Inovasi Pembelajaran Digital

Menggunakan Model Blended POE2WE di Era Revolusi Industri 4.0. Prosiding

SNFA (Seminar Nasional dan Aplikasinya), 82-90

\begin{tabular}{|c|c|c|}
\hline Fase- fase & Kegiatan Guru & Kegiatan Peserta Didik \\
\hline Prediction & $\begin{array}{ll}\text { - } & \text { Menyampaikan tujuan } \\
& \text { pembelajaran. } \\
\text { - } & \text { Mengajukan pertanyaan } \\
& \text { kepada siswa } \\
\text { - } & \text { Menginventarisir prediksi } \\
& \text { dan alasan yang di } \\
\text { kemukakan peserta didik. }\end{array}$ & $\begin{array}{ll}\text { - } & \text { Memperhatikan penjelasan } \\
\text { dari guru. } & \\
\text { - } & \text { Memprediksi jawaban } \\
\text { pertanyaan dari guru } \\
\text { - } \begin{array}{l}\text { Mendiskusikan hasil } \\
\text { prediksinya }\end{array}\end{array}$ \\
\hline Observation & $\begin{array}{llr}\text { - } & \text { Mendorong peserta didik } \\
& \text { untuk bekerja } & \text { secara } \\
& \text { kelompok } & \\
\text { - } & \text { Membagikan LKS } & \\
\text { - } & \text { Mengawasi } & \text { kegiatan } \\
& \text { percobaan yang dilakukan } \\
& \text { oleh peserta didik } & \end{array}$ & $\begin{array}{llr}\text { - } & \text { Membentuk kelompok } \\
\text { - } & \text { Melakukan percobaan } \\
\text { - } & \begin{array}{l}\text { Mengumpulkan data } \\
\text { percobaan hasil }\end{array} \\
\text { - } & \begin{array}{l}\text { Melakukan } \\
\text { kelompok diskusi }\end{array} \\
\text { - } & \begin{array}{l}\text { Menyimpulkan } \\
\text { percobaan }\end{array} & \text { hasil }\end{array}$ \\
\hline Explanation & $\begin{array}{lll}\text { - } & \begin{array}{l}\text { Mendorong peserta } \\
\text { untuk menjelaskan }\end{array} & \text { hasil } \\
\text { percobaan. } & \\
\text { - } & \begin{array}{l}\text { Meminta peserta } \\
\text { pempresentasikan }\end{array} & \text { didik } \\
\text { percobaannya } & \\
\text { - } & \begin{array}{l}\text { Mengklarifikasikan } \\
\text { percobaannya }\end{array} & \text { hasil } \\
\end{array}$ & $\begin{array}{l}\text { - Mengemukakan } \\
\text { pendapatnya tentang hasil } \\
\text { percobaan } \\
\text { Mengemukakan } \\
\text { pendapatnya tentang } \\
\text { gagasan baru berdasarkan } \\
\text { hasil percobaan. } \\
\text { - Menanggapi presentasi dari } \\
\text { kelompok lain. }\end{array}$ \\
\hline
\end{tabular}




\begin{tabular}{|c|c|c|}
\hline & $\begin{array}{l}\text { - Menjelaskan konsep/definisi } \\
\text { baru }\end{array}$ & $\begin{array}{l}\text { Konsep baru dari guru dapat } \\
\text { di terima }\end{array}$ \\
\hline Elaboration & $\begin{array}{l}\text { Memberi permasalahan } \\
\text { berkaitan dengan penerapan } \\
\text { konsep. } \\
\text { Mendorong peserta didik } \\
\text { untuk menerapkan konsep } \\
\text { baru dalam situasi baru }\end{array}$ & $\begin{array}{l}\text { Menerapkan konsep baru } \\
\text { dalam situasi baru atau } \\
\text { kehidupan sehari-hari. }\end{array}$ \\
\hline Write & 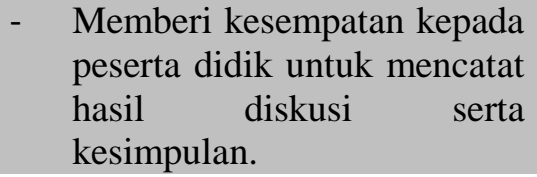 & $\begin{array}{l}\text { - Mencatat hasil penjelasan } \\
\text { dan kesimpulan dari guru } \\
\text { dan diskusi kelompok }\end{array}$ \\
\hline Evaluation & $\begin{array}{ll}\text { - } & \text { Mengajukan pertanyaan } \\
\text { untuk penilaian proses } \\
\text { - } & \text { Menilai pengetahuan peserta } \\
\text { didik } & \\
\text { - } & \begin{array}{l}\text { Memberikan } \\
\text { terhadap jawaban }\end{array} \\
\text { didik } & \text { peserta }\end{array}$ & $\begin{array}{ll}\text { - } & \text { Menjawab pertanyaan } \\
\text { berdasarkan data } & \\
\text { - } & \begin{array}{l}\text { Mendemonstrasikan } \\
\text { kemampuan dalam } \\
\text { penguasaan konsep }\end{array}\end{array}$ \\
\hline
\end{tabular}

B. SAVI (Somatic, Auditory, Visual,

\section{Intellectual)}

Miratus (2013) menjelaskan bahwa kelebihan model pembelajaran SAVI, diantaranya adalah: (1) membangkitkan kecerdasan siswa secara terpadu melalui penggabungan gerak fisik dengan aktivitas intelektual; (2) siswa tidak mudah lupa karena siswa membangun sendiri pengetahuannya; (3) suasana dalam proses pembelajaran menyenangkan; memupuk kerjasama; (5) membangkitkan kreativitas, keterampilan, dan motivasi belajar siswa; (6) melatih siswa untuk terbiasa berpikir dan mengemukakan pendapat dan berani menjelaskan jawabannya; (7) variasi yang cocok untuk semua gaya belajar. Model SAVI sangat berkaitan dengan penanaman nilai karakter, khususnya kreativitas belajar siswa.
Menurut Andrianti, dkk (2016) Pendekatan SAVI merupakan suatu pendekatan pembelajaran yang mengacu pada dimensi manusia. Di mana pada dasarnya, manusia memiliki empat dimensi yakni tubuh atau somatis (S), pendengaran atau auditori (A), penglihatan atau visual (V), dan pemikiran atau intelektual (I). Dalam pembelajaran dengan menggunakan pendekatan SAVI akan melibatkan emosi, seluruh tubuh, semua indera, serta keluasan pribadi dengan menyadari bahwa setiap orang belajar memiliki cara yang berbeda. Sesuai dengan pernyataan di atas, maka dapat dikatakan pendekatan SAVI adalah belajar berdasarkan aktivitas siswa yang bergerak aktif secara fisik ketika belajar melalui pemanfaatan indera sebanyak mungkin dan membuat seluruh tubuh atau pikiran ikut terlibat dalam proses pembelajaran 


Menurut
langkah model pembelajaran SAVI
sebagai berikut (dalam Kurnianti,
2016:8):

Tahap persiapan. Tahap ini berkaitan dengan mempersiapkan siswa untuk belajar. keterampilan guru dalam memotivasi siswa sangat diperlukan untuk memberikan perasaan positif mengenai pengalaman belajar yang akan dilaksanakan sehingga siswa siap mengikuti pembelajaran

Tahap penyampaian. Tahap ini mempunyai tujuan untuk membantu siswa menemukan materi belajar yang baik dengan cara yangmenarik dan menyenangkan melalui kegiatan yang melibatkan panca indra.

Tahap pelatihan. Tahap ini guru membantu siswa untuk mengintegrasikan dan memadukan pengetahuan atau keterampilan baru dengan berbagai cara. Tahap pelatihan bertujuan agar siswa mampu mengintegrasi dan menyerap pengetahuan dan keterampilan baru secaraoptimal.

Tahap penampilan. Tahap ini membantu siswa menerapkan dan mengembangkan pengetahuan serta keterampilan baru mereka pada pekerjaan sehingga hasil belajar terus meningkat.

Puspitasari (2018) Kelebihan model pembelajaran SAVI diantaranya meningkatkan kecerdasan secara terpadu siswa secara penuh melalui penggabungan gerak fisik dengan aktivitas intelektual, suasana dalam pembelajaran menjadi menyenangkan karena siswa merasa diperhatikan sehingga tidak bosan dalam belajar, Menciptakan suasana belajar yang lebih menarik dan efektif.

Kekurangan model pembelajarna SAVI diantaranya membutuhkan perubahan agar sesuai dengan situasi pembelajaran, banyak guru yang belum mengetahui model pembelajaran SAVI.

Berdasarkan uraian di atas, penulis tertarik untuk melakukan penelitian tentang "Inovasi Model Pembelajaran POE2WE dengan Berbasis Savi (Somatic, Auditory, Visual, Intellectual) Pada Materi Fisika". Uraian latar belakang tersebut, perlu adanya pengembangan bahan ajar berbentuk model pembelajaran POE2WE dengan berbasis SAVI untuk meningkatkan hasil belajar siswa.

\section{METODE PENELITIAN}

Didalam penelitian ini digunakan penelitian studi pustaka dan tes soal dengan subjek mahasiswa p.fisika 18 dengan jumlah 33 orang, dengan variabel tertutup dengan desain Pre-test and Post-test Group dengan pola:

\section{$\mathrm{O}_{0} \times \mathrm{O}_{1}$}

Keterangan: 
$\mathrm{O}_{0}=$ Nilai pre-test sebelum diajar dengan model pembelajaran POE2WE Berbasis SAVI

$\mathrm{O}_{1}=$ Nilai post-test setelah diajar dengan model pembelajaran POE2WE Berbasis SAVI

$\mathrm{X}=$ Perlakuan yang diberikan

Kemudian instrument penelitian sebelum digunakan sebagai tes hasil belajar, terlebih dahulu diuji cobakan untuk menentukan validitas dan realibilitas tes. Data utama yaitu tentang skor hasil belajar fisika. Selanjutnya, data tentang hasil belajar fisika dianalisis menggunakan statistik deskriptif karena dalam penelitian ini untuk mengetahui besarnya hasil belajar fisika sebelum dan setelah diajar model pembelajaran POE2WE berbasis SAVI.

Hasil penelitian yang diperoleh terdiri atas data awal dan data akhir kemudian dihitung peningkatan skor yang dapat dijelaskan dengan nilai $\mathrm{N}$-gain (selisih antara skor akhir dan skor awal). N-gain diperoleh dari skor post-test dikurangi dengan skor pretest. Standard gain dapat dihitung dengan menggunakan rumus berikut:

$g$ $=\frac{\text { posttest score }- \text { pre test score }}{\text { maximum possible score }- \text { pre test score }}$

Dengan kriteria interpretasi indeks gain, yaitu:

Tabel 2. Kriteria Indeks Gain

\begin{tabular}{lc}
\hline \multicolumn{1}{c}{ Indeks Gain } & Kriteria \\
\hline $\mathrm{g}>86$ & Tinggi \\
$80 \geq \mathrm{g} \geq 85$ & Sedang \\
\hline
\end{tabular}

\section{$60 \geq \mathrm{g}$}

Rendah

\section{HASIL DAN PEMBAHASAN}

Analisis deskriptif hasil belajar Fisika melalui I model pembelajaran POE2WE berbasis SAVI Terhadap Hasil Belajar Fisika Peserta Didik mahasiswa p.fisika 18 dapat dilihat pada Tabel 3:

Tabel 3. Analisis Deskriptif Skor Peserta Didik mahasiswa p.fisika 18 pada Saat Pretest Dan Postest

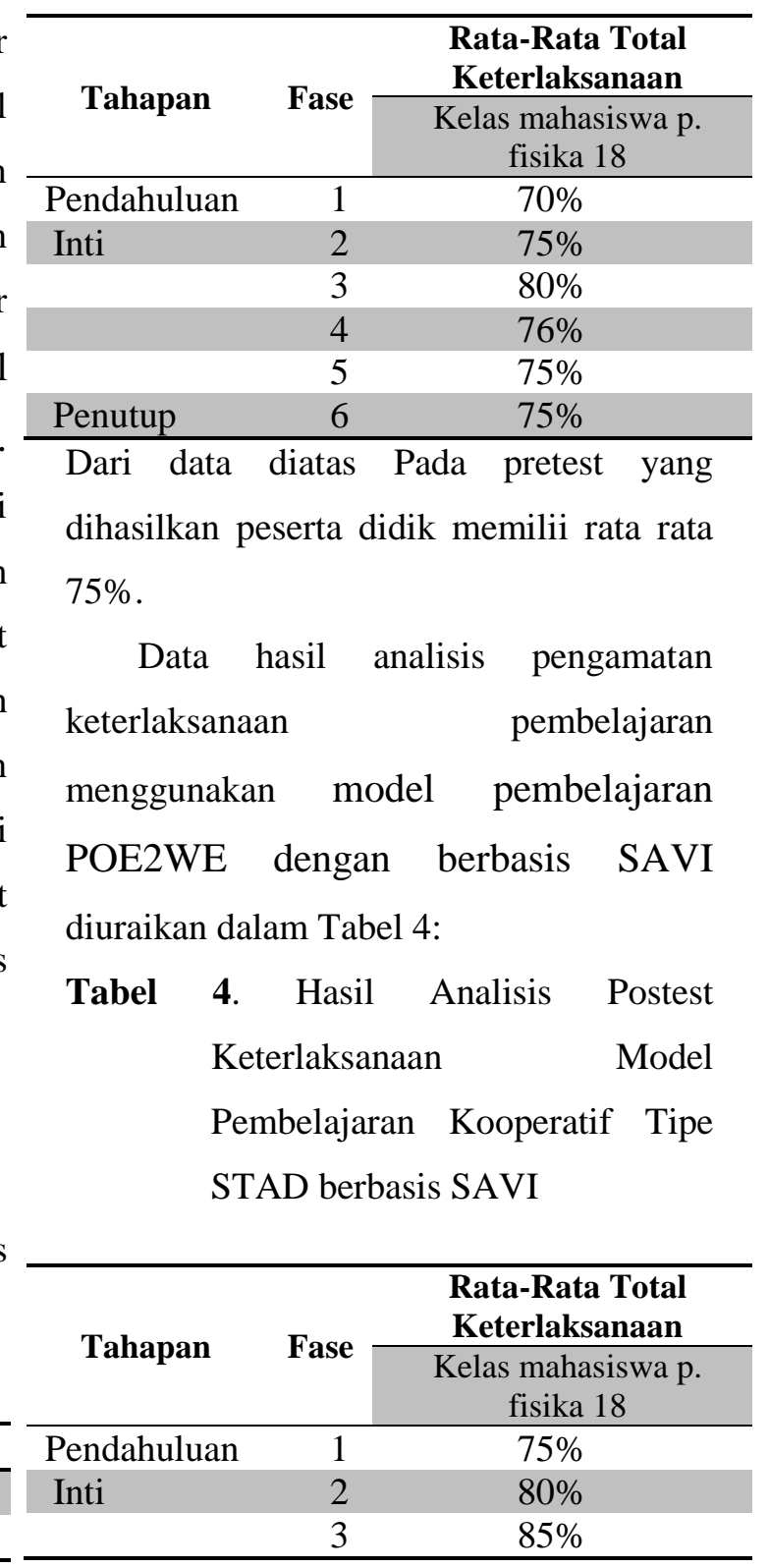




\begin{tabular}{rrr}
\hline & 4 & $80 \%$ \\
Penutup & 5 & $85 \%$ \\
\hline & 6 & $85 \%$ \\
\hline
\end{tabular}

(Irani, A. dkk, 2018)

Pada Postest yang diterapkan memperoleh nilai rata-rata total lebih dari $81 \%$ yang berarti kegiatan guru dengan menerapkan model pembelajaran POE2WE dengan berbasis SAVI ini telah dilakukan dengan sangat baik. Berikut fase-fase model pembelajaran POE2WE (Nana dkk, 2016): fase (1) Prediction, memberikan pertanyaan berupa prediksi kepada peserta didik, fase (2) Observation, mendorong peserta didik untuk bekerja secara kelompok, fase (3) Explanation, mendorong peserta didik untuk menjelaskan hasil percobaan, fase (4) Elaboration, memberi permasalahan berkaitan dengan penerapan konsep, fase (5) Write, memberi kesempatan kepada peserta didik untuk mencatat hasil diskusi serta kesimpulan , dan fase (6) Evaluation, Mengajukan pertanyaan untuk penilaian proses.

Data hasil pengamatan aktivitas somatis, audio, visual dan intelektual peserta didik dari dua pertemuan masingmasing di kelas mahasiswa p. fisika 18 , sehingga kita dapat mengetahui persentase aktivitas dominan yang dilakukan oleh setiap peserta didik dalam proses pembelajaran dengan menggunakan model pembelajaran POE2WE dengan berbasis SAVI. Rata-rata total persentase data hasil pengamatan aktivitas peserta didik pada setiap kelompok di kelas tersebut disajikan pada Tabel 5:

Tabel 5. Rata-Rata Persentase Total Aktivitas Siswa

\begin{tabular}{lccc}
\hline \multirow{2}{*}{ Kelompok } & \multicolumn{3}{c}{$\begin{array}{l}\text { Rata-Rata Persentase Total } \\
\text { Kelas mahasiswa p. fisika 18 }\end{array}$} \\
\cline { 2 - 4 } & 25 & 5 orang & 3 orang \\
\hline Somatis & 80 & 75 & 71 \\
Auditori & 82 & 80 & 76 \\
Visual & 85 & 84 & 79 \\
Intelektual & 85 & 84 & 80 \\
Rata rata & 85 & 84 & 79 \\
\hline
\end{tabular}

Berdasarkan rata-rata persentase aktivitas siswa dapat terlihat bahwa setiap kelompok akan cenderung memiliki persentase aktivitas terbesar sesuai dengan gaya belajarnya yang dominan pada kategori baik sehingga gaya belajar yang dimiliki setiap siswa dapat dimaksimalkan dengan baik pada model pembelajaran POE2WE dengan berbasis SAVI.

Untuk hasil rata-rata $n$-gain mahasiswa p.fisika 18 disajikan pada Tabel 6:

Tabel 6. N-Gain Rata-rata

\begin{tabular}{|c|c|c|}
\hline $\begin{array}{l}\text { Jumlah } \\
\text { Peserta }\end{array}$ & N-Gain & Kriteria \\
\hline 25 & 85 & Sedang \\
\hline 5 & 84 & Sedang \\
\hline 3 & 79 & Rendah \\
\hline \multicolumn{3}{|c|}{$\begin{array}{l}\text { Berdasarkan Tabel } 6 \text { diperoleh nilai gain } \\
\text { pada mahasiswa p.fisika } 18 \text { dengan kriteria } \\
\text { sedang. Dapat disimpulkan bahwa model } \\
\text { pembelajaran POE2WE berbasis SAVI } \\
\text { pada materi fisika dapat meningkatkan } \\
\text { hasil belajar siswa secara signifikan dengan }\end{array}$} \\
\hline & & \\
\hline
\end{tabular}


Peningkatan hasil belajar siswa ini sesuai dengan tujuan pembelajaran kooperatif menurut Slavin (2011) bahwa pembelajaran kooperatif akan lebih memudahkan siswa dalam menemukan dan memahami konsep yang sulit apabila mereka dapat saling mendiskusikam masalah-masalah tersebut dengan temannya. Serta melalui pendekatan SAVI mampu mengakomodasi karakteristik siswa yang berbeda dengan memanfaatkan seluruh indera yang dimiliki siswa saat pembelajaran. Dengan memaksimalikan gaya belajar yang dimiliki siswa maka diharapkan dapat meningkatkan hasil belajar dan respon siswa terhadap pembelajaran di kelas (Meier, 2000).

\section{PENUTUP}

\section{A. Kesimpulan}

Berdasarkan hasil data yang diperoleh dalam penelitian ini, maka dapat disimpulkan sebagai berikut:

1. Penggunaan model (Prediction, Observation, Explanation, Elaboration, Write dan Evaluation) POE2WE berbasis (Somatic, Auditory, Visual, Intellectual) SAVI dapat meningkatkan hasil belajar peserta didik.

2. Hasil belajar fisika peserta didik mahasiswa p.fisika 18 sebelum diterapkan Model pembelajaran POE2WE berbasis SAVI rata rata sebesar $75 \%$
3. Hasil belajar fisika peserta didik mahasiswa p.fisika 18 setelah diterapkan Model pembelajaran POE2WE berbasis SAVI rata rata sebesar $81 \%$

4. Hasil belajar peserta didik mahasiswa p.fisika 18 yang diajar dengan menggunakan model pembelajaran POE2WE berbasis SAVI mengalami peningkatan, ini ditunjukkan pada skor rata-rata posttest yang kita peroleh lebih besar daripada skor rata-rata yang diperoleh pada pretest dan dengan perhitngan $\mathrm{N}$ Gain berada pada kategori sedang.

\section{B. Saran}

Berdasarkan simpulan, maka peneliti memberikan saran untuk perbaikan bagi penelitian selanjutnya, yaitu:

1. Bagi guru, agar penelitian ini dapat dipergunakan sebagai acuan untuk dapat mengembangkan model-model mengajar yang bervariasi sehingga tidak membosankan bagi peserta didik

2. Bagi peneliti selanjutnya, apabila ingin melakukan penelitian dengan judul yang sama agar penelitian yang dilakukan lebih disempurnakan lagi.

3. Bagi pengembangan ilmu, diharapkan mvodel pembelajaran dapat menjadi salah satu alternatif model pembelajaran yang diterapkan pada mata pelajaran Fisika untuk meningkatkan hasil belajar peserta 
didik melalui model pembelajaran inkuiri terbimbing.

4. Diharapkan pada penelitian selanjutnya tidak hanya sebatas penerapan pembelajaran dengan model POE2WE berbasis SAVI saja melainkan adanya perangkat yang telah dikembangkan dengan baik untuk model pembelajaran ini

\section{UCAPAN TERIMA KASIH}

Alhamdulillah puji syukur kepada Allah swt, karena kehendak dan ridhaNya peneliti dapat menyelesaikan jurnal ini. Peneliti sadari jurnal ini tidak akan selesai tanpa doa, dukungan dan dorongan dari berbagai pihak. Adapun dalam kesempatan ini peneliti ingin mengucapkan banyak terima kasih kepada:

1. Dr. Nana M.Pd. selaku dosen pengampu mata kuliah Fisika Sekolah 2

2. Semua pihak yang tidak dapat disebutkan satu persatu, terima kasih atas segalanya.

\section{PUSTAKA}

Gilakjani, A.P. (2011). Visual, Auditory, Kinaesthetic Learning Styles and Their Impacts on English Language Teaching. Journal of Studies in Education. 2(1), pp.104-113

Hannah, N. (2009). Penerapan Pendekatan SAVI Untuk Meningkatkan Hasil Belajar Siswa Pada Mata Pelajaran Faroidh Kelas VIII di MTs. Nurul Amanah Madura. Thesis Tidak Dipublikasikan,
Irani,A., dan Dwikoranto. 2018. Penerapan model pembelajaran kooperatif tipe stad berbasis savi untuk meningkatkan hasil belajar siswa pada sub bab pemantulan cahaya. 18(02), 101-105.

Meier, D. (2000). The Accelerated Learning Handbook. United States of Americ: The McGraw-Hill Companies, Inc

Miratus, D. (2013). Makalah Model Pembelajaran SAVI. Diperoleh 7 Februari 2020, dari http://dyamiratus.blogspot.com

Nana. 2014. Pengembangan model POE2WE dalam pembelajaran Fisika SMA. Universitas Sebelas Maret.

Nana. 2016. Pengembangan Model Pembelajaran Prediction, Observation, Explanation, Elaboration, Write, and Evaluating (POE2WE) dalam Pembelajaran Fisika SMA. Universitas Sebelas Maret.

Nana, N., \& Surahman, E. Pengembangan Inovasi Pembelajaran Digital Menggunakan Model Blended POE2WE di Era Revolusi Industri 4.0. In Prosiding SNFA (Seminar Nasional Fisika dan Aplikasinya) (Vol. 4, pp. 82-90).

Nana, N. (2019, February). The Implementation of POE2WE Model Using Scientific Approach in Linear Learning in Senior High School. In Prosiding SNFA (Seminar Nasional Fisika dan Aplikasinya) (Vol. 3, pp. 196-205).

Nana, D. R., \& Muhammad, A. Sajidan 2016 The Effectiveness of Scientific Approach Through Predict, Observe, Explain, Elaborate, Write and Evaluation (POE2WE) Model on the Topic of Kinetics (Rectilinear Motion) at Senior High School. The Social Sciences, 11(6), 1028-1034.

Nana, S., Akhyar, M., \& Rochsantiningsih, D. (2014). The Development Of Predict, Observe, Explain, Elaborate, Write, And 
Evaluate (POE2WE) Learning Model In Physics Learning At Senior School. Development, 5(19).

Noviyanti, L.,Sukarmin., Suparmi. 2016. Pengembangan modul fisika berbasis somatic, auditory, visual, intellectual (savi) untuk meningkatkan kreativitas belajar siswa kelas x sma/ma dengan topik kalor dan perpindahannya. Universitas Sebelas Maret.

Permatasari, O. I. (2011). Keefektifan model pembelajaran PredictObserve-Explain (POE) berbasis kontekstual dalam peningkatan aktivitas dan hasil belajar siswa SMP kelas VIII pada pokok bahasan tekanan. Universitas Negeri Semarang.

Rahayu, F. A. (2013). Pengembangan Modul Keanekaragaman Reptilia Berbasis Museum Biologi UGM Sebagai Bahan Ajar Mandiri Siswa SMA/MA Kelas X. Skripsi Tidak
Dipublikasikan, Universitas Islam Sunan Kalijaga, Yogyakarta

Rahayu, S., Widodo, A. T., \& Sudirman. (2013). Pengembangan perangkat pembelajaran model $P O E$ berbantuan media "I am Scientist". Innovatif: Journal of Curriculum and Education Technology, 2(1), 128-133.

Samosir, H. 2010. Model Pembelajaran Predict-Observe-Explain-Write (POEW) untuk meningkatkan penguasaan konsep kalor dan keterampilan berpikir kritis siswa SMA. Universitas Pendidikan Indonesia.

Slavin, R.E. 2008. Cooperative Learning. Bandung: Nusa Media

Taufik, M. 2010. Desain Model Pembelajaran Untuk Meningkatkan Kemampuan Pemecahan Masalah Dalam Pembelajaran IPA (Fisika) Sekolah Menengah Pertama di Kota Bandung. Jurnal Berkala Fisika. 13(2), Halaman E31-E44 